\title{
Intense Focus of Alveolar Echinococcosis, South Kyrgyzstan
}

\section{Bakhadyr Bebezov, Nurlan Mamashev, Tilek Umetaliev, Iskender Ziadinov, Philip S. Craig, Deborah E. Joekel, Peter Deplazes, Felix Grimm, Paul R. Torgerson}

Human alveolar echinococcosis (AE) is a highly pathogenic zoonotic parasitic disease caused by Echinococcus multilocularis. An ultrasound study in southern Kyrgyzstan during 2012 revealed a prevalence of $4.2 \%$ probable or confirmed $\mathrm{AE}$ and an additional $2.2 \%$ possible $\mathrm{AE}$, representing an emerging situation. The risk for probable or confirmed AE was significantly higher in dog owners.

$\mathrm{H}$ uman alveolar echinococcosis (AE), caused by the larval stage of Echinococcus multilocularis, is a lethal parasitic zoonosis if untreated $(1,2)$. In China, hyperendemic foci of disease have been described (3) with prevalences $>5 \%$. AE incidence recently has increased in Europe (4). In Kyrgyzstan, the disease incidence has increased rapidly since 2000; a total of $148 \mathrm{AE}$ cases were reported in 2013 (5).

Hospital records for AE notifications identified a cluster of cases in the Alay Valley in southern Kyrgyzstan. Therefore, in 2012, we conducted an ultrasound study of the population of Sary Mogol (location $39.66^{\circ} \mathrm{N}, 72.88^{\circ} \mathrm{E}$ ) to determine the extent of infection and to investigate the epidemiology of the disease in this district.

\section{The Study}

The study was a census type of design. We obtained informed consent from each study participant or, for children, consent from parents. Participants were interviewed using a questionnaire in Kyrgyz and given an abdominal ultrasound examination. For participants with hepatic lesions suspected to be $\mathrm{AE}$ or cystic echinococcosis (CE) or who reported previous treatment for echinococcosis, a venous blood sample was taken for further analysis. The Ministry of Health of the Kyrgyz Republic provided ethics approval for this study.

We detected specific IgG from collected serum in 3 genus-specific ELISAs based on E. granulosus hydatid fluid,

Author affiliations: Kyrgyz-Russian Slavic University, Bishkek, Kyrgyzstan (B. Bebezov, N. Mamashev, T. Umetaliev); University of Zurich, Zurich, Switzerland (I. Ziadinov, D.E. Joekel, P. Deplazes, F. Grimm, P.R. Torgerson); University of Salford, Greater Manchester, UK (P.S. Craig)

DOI: https://doi.org/10.3201/eid2406.161641 native protoscolex antigens, and antigen B (6). Specific antibodies against $E$. multilocularis were demonstrated using affinity purified Em2G11 antigen ( 6 ) and the recombinant Em18 antigen (7). We further investigated persons who were negative in these ELISAs with a commercial Western blot (Echinococcus western blot IgG; LDBio Diagnostics, Lyon, France).

Where possible, we followed participants to treatment. For some patients we obtained samples from resected lesions. DNA was isolated, followed by amplification of part of the E. multilocularis mitochondrial $12 \mathrm{~S}$ rRNA gene (8). Confirmation of diagnosis was also achieved by histologic examination of the resected lesions. Possible AE cases were those with ultrasound lesions and no follow-up. Probable cases additionally had positive serologic results, and confirmed cases were positive by histology, PCR, or both.

We analyzed data with all AE cases and with probable or confirmed $\mathrm{AE}$ as the dependent variable using a relative risk generalized linear model (GLM). We analyzed differences in lesion sizes between seropositive and seronegative groups by the Wilcoxon test and used Fisher exact test to examine differences in seroprevalence between persons with confirmed $\mathrm{AE}$ and persons with only an ultrasound diagnosis.

We examined 1,617 persons (Figure 1) (48\% of the population of the district; online Technical Appendix, https:// wwwnc.cdc.gov/EID/article/24/6/16-1641-Techapp1.pdf). Of these, 106 persons had ultrasound findings consistent with $\mathrm{AE}$ (including 1 concomitantly infected with $\mathrm{CE}$ ). Probable or confirmed cases (online Technical Appendix) with $\geq 2$ diagnostic criteria (Figure 1) were subsequently diagnosed in $68(4.2 \%)$ persons leaving $36(2.2 \%)$ with possible AE. Three $(0.2 \%)$ additional persons had lesions suggestive of CE. For 9 persons, images were recorded as inconclusive.

The GLM demonstrated an increase in the risk for possible infection with $\mathrm{AE}$ in dog owners, male patients, and persons who practiced home slaughter of livestock. Only dog ownership increased the risk for probable AE infection (Table 1).

Of the 106 persons in whom AE was diagnosed, we detected specific antibodies in $40(42.1 \%)$ of the 95 available serum samples by 3 different ELISAs (Table 2). Western blot analysis of negative serum identified specific antibodies on Echinococcus genus level in 9 additional patients. Thus, 49 of the 95 persons had serologic evidence of infection. Lesions, measured in 53 patients, ranged from 


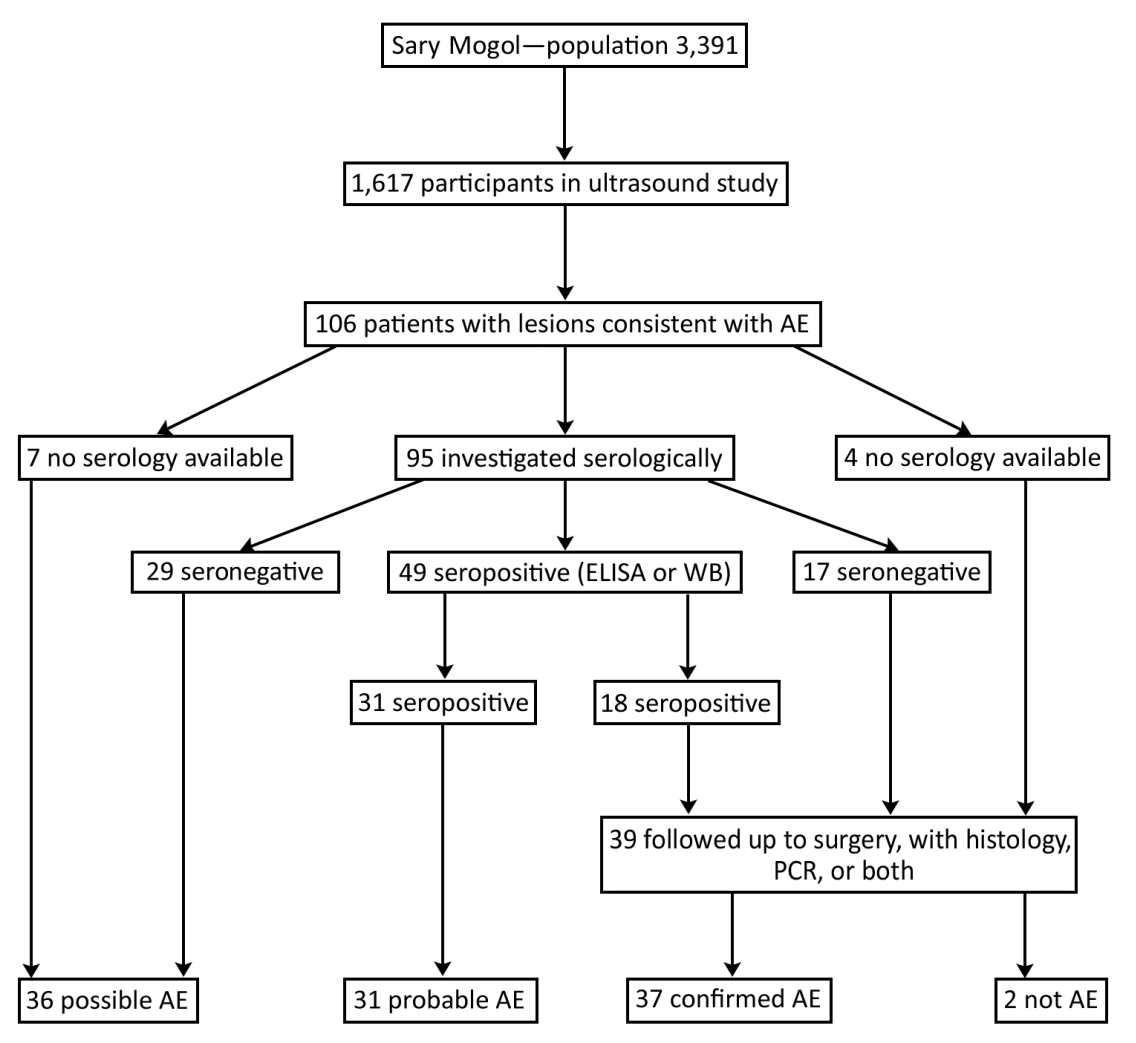

Figure 1. Flowchart of patient selection, ultrasound investigation, serologic testing, and case definitions in a study of $A E$, southern Kyrgyzstan, 2012. AE, alveolar echinococcosis; WB, Western blot.

5 to $197 \mathrm{~mm}$ (mean $28 \mathrm{~mm}$ ). The mean size of lesions in the 22 ELISA- or Western blot-seropositive persons was $46.1 \mathrm{~mm}$, significantly larger than the mean size of 11.0 $\mathrm{mm}$ for lesions from the 27 seronegative patients $(\mathrm{p}=0.01$; Figure 2).

By September 2017, a total of 39 persons were known to have been treated by hepatic surgery. Among them, AE was confirmed in $37(94.7 \%)$ by histology, PCR, or both. From these 37 persons, 35 serum samples were available; $18(51.4 \%)$ showed serologic evidence of infection. This finding did not differ significantly from the proportion of persons without follow-up data who had serologic evidence of infection (31/61) (Figure 1).

The decreasing risk for possible AE with increasing age, contrasting with findings in areas of China where AE is highly endemic (9), indicates different dynamics and hence reflect an emerging epidemic of human $\mathrm{AE}$ in Kyrgyzstan. Consequently, this observation supports the hypothesis that the epidemic could be linked to the dissolution of the Soviet Union in 1991 (5). In our study, the higher risk for possible $\mathrm{AE}$ in male than in female patients contrasts with risk in areas of western China where $\mathrm{AE}$ is endemic. The reasons for this difference are unclear but might reflect behavioral (e.g., rates of dog contact) or cultural reasons that result in a greater risk for exposure for female persons in China (9) and for male persons in Kyrgyzstan. However, both risk factors disappear if only probable or confirmed $\mathrm{AE}$ is used as the case definition for AE.

The poorer sensitivity $(\approx 50 \%-60 \%)$ of the serologic tests as compared with the validations in Switzerland (6) might result from cases in Switzerland being

Table 1. Relative risk from multivariable analysis of persons with an ultrasound diagnosis of $A E$ and persons with a probable or a confirmed diagnosis of $A E$, southern Kyrgyzstan, 2012*

\begin{tabular}{lcc}
\hline Dependent variable, risk factor & Relative risk $(95 \% \mathrm{Cl})$ & $\mathrm{p}$ value \\
\hline Ultrasound diagnosis of AE & & \\
Patient age† & $0.982(0.969-0.995)$ & 0.0074 \\
Male sex & $1.56(1.07-2.29)$ & 0.021 \\
Dog ownership & $1.82(1.24-2.72)$ & 0.0025 \\
Home slaughter of livestock & $1.60(1.03-2.56)$ & 0.043 \\
Dog ownership among persons with probable and confirmed AE $\neq$ & $2.81(1.64-5.09)$ & 0.00033 \\
\hline
\end{tabular}

*Probable diagnosis: ultrasound and serology; confirmed diagnosis: ultrasound and histology/PCR. AE, alveolar echinococcosis.

†Median age of persons with possible $A E$ was $24 \mathrm{y}$; median age of $A E$-negative persons was $28 \mathrm{y}$.

$\ddagger$ †og ownership was the only risk factor remaining as significant when only probable and confirmed AE were analyzed as the dependent variables. 
Alveolar Echinococcosis, Kyrgyzstan

Table 2. Ultrasound results partially confirmed with $\mathrm{PCR} /$ histology for $\mathrm{AE}$ or $\mathrm{CE}$ in relation to serology, southern Kyrgyzstan, 2012*

\begin{tabular}{|c|c|c|c|c|c|c|c|c|c|}
\hline \multirow[b]{2}{*}{ Ultrasound results } & \multicolumn{4}{|c|}{ ELISA } & \multicolumn{5}{|c|}{ WB† } \\
\hline & $\begin{array}{c}\text { No. available } \\
\text { samples } f\end{array}$ & $\mathrm{Neg}$ & AE/CE\$ & AEd & $\begin{array}{c}\text { No. available } \\
\text { samplesf }\end{array}$ & Neg & $\mathrm{AE} / \mathrm{CE}$ & CE & $\mathrm{AE}$ \\
\hline$A E, n=106$ & 95 & 55 & 25 & 15 & 43 & 34 & 6 & 3 & 0 \\
\hline Confirmed $A E, \# n=37$ & 33 & 18 & 10 & 5 & 13 & 10 & 3 & 0 & 0 \\
\hline Inconclusive, $\mathrm{n}=9$ & 6 & 5 & 1 & 0 & 4 & 4 & 0 & 0 & 0 \\
\hline$C E, n=3$ & 3 & 2 & 1 & 0 & 0 & 0 & 0 & 0 & 0 \\
\hline$C E$ and $A E, n=1$ & 1 & 0 & 1 & 0 & 0 & 0 & 0 & 0 & 0 \\
\hline Negative but with history of CE/AE, $n=13$ & 6 & 1 & 3 & 2 & 1 & 1 & 0 & 0 & 0 \\
\hline $\begin{array}{l}\text { *AE/CE indicates the test is specific only to genu } \\
\text { †ELISA-negative serum only. } \\
\text { fNot every patient for whom echinococcosis was } \\
\text { sample. For some of these patients, insufficient } s \\
\text { §E. granulosus hydatid fluid and/or native protos } \\
\text { TEm18 and/or EmG11 positive (E. granulosus hy } \\
\text { \#Diagnosis confirmed by PCR and/or histology o }\end{array}$ & $\begin{array}{l}\text { level. AE, alveole } \\
\text { liagnosed by ultr } \\
\text { rum was availabl } \\
\text { lex antigens and } \\
\text { atid fluid and/or } r \\
\text { esected lesion. }\end{array}$ & $\begin{array}{l}\text { sound } \\
\text { from } t \\
\text { or antic } \\
\text { ative pr }\end{array}$ & $\begin{array}{l}\text { coccosis; C } \\
\text { ad inconclu } \\
\text { e blood sar } \\
\text { en B positiv } \\
\text { toscolex ar }\end{array}$ & $\begin{array}{l}\text { e resu } \\
\text { le to ur } \\
\text { out Em } \\
\text { ens ar }\end{array}$ & $\begin{array}{l}\text { a history of echir } \\
\text { ake both ELISA a } \\
\text { d EmG11 negati } \\
\text { antigen B positive }\end{array}$ & $\begin{array}{l}\operatorname{coccos} \\
\text { WB. }\end{array}$ & provide & blood & \\
\hline
\end{tabular}

at a more advanced stage of clinical disease. The fact that persons with larger lesions were more likely to be seropositive indicates that seroconversion might not occur either during the early stages of the disease or when only abortive lesions are present. Similar patterns of low seroreactivity were observed in the AE endemic focus in south Gansu (China) (10) and included persons with possible abortive forms of the disease. In addition, the mean age of ultrasound-positive persons in our study is 9 years younger than those receiving surgical treatment resulting from clinical disease, indicating that our study has detected an early stage of the disease in these persons. In the patients followed up, the seropositivity rate for those with $\mathrm{AE}$ confirmed by histopathology did not differ significantly from the rate for those with only

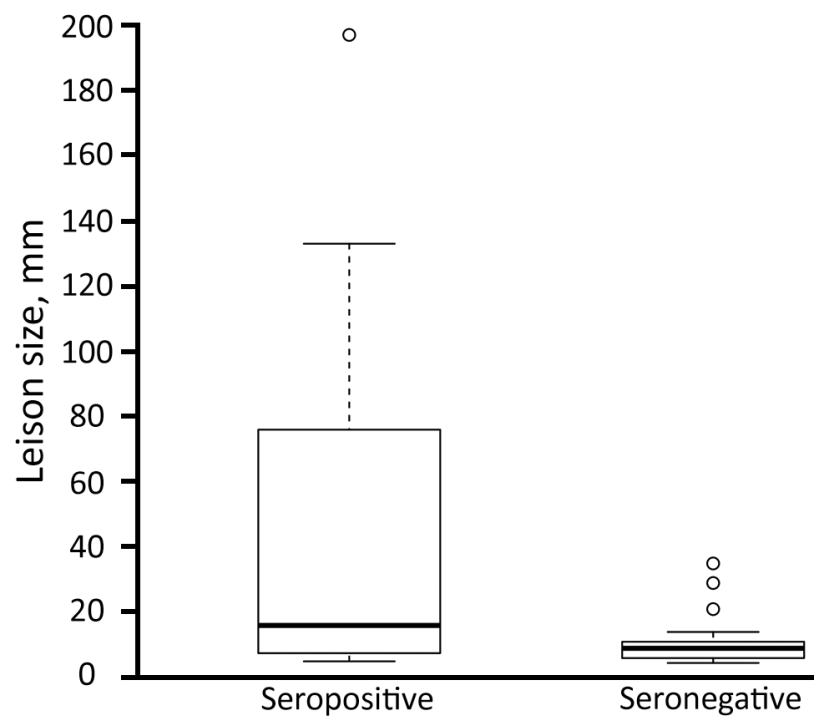

Figure 2. Differences in sizes of lesions ( $n=49$ serum samples available from 57 patients with measured lesions) diagnosed in persons seropositive by ELISA, Western blot, or both $(n=27)$ or seronegative $(n=22)$ in a study of alveolar echinococcosis, southern Kyrgyzstan, 2012. Box plots indicate interquartile range (box top and bottom), median (black horizontal line), 1.5 times interquartile range (error bars), and extreme values (circles). an ultrasound diagnosis. Thus, we can conclude that the same proportion of patients without histologic or PCR confirmation (to date) are likely to have AE. Although the diagnostic efficiency of ultrasound should be estimated with caution, these results might indicate a specificity as high as $99.7 \%$ (online Technical Appendix). However, including only probable or confirmed cases in the regression analysis increased the association with dog ownership while eliminating other risk factors. This finding might indicate that some of the possible AE cases are not AE. Nevertheless, specificity of ultrasound in this scenario remains at $97.4 \%$.

\section{Conclusions}

We documented a highly endemic focus of human AE in which the prevalence of confirmed or probable $\mathrm{AE}$ was $\approx 4.2 \%$ in southern Kyrgyzstan. A characteristic of communities with high levels of human $\mathrm{AE}$ are concomitant high prevalences of E. multilocularis in the dog population, such as western Sichuan Province (11). The mole vole (Ellobius tancrei) has recently been confirmed as a natural intermediate host of E. multilocularis in Sary Mogol and has identical DNA sequence for the E. multilocularis haplotype described in feces of local domestic dogs (12). In Kyrgyzstan, prevalences in dogs of $20 \%$ have been observed (13). In our study, dog owners had 1.8 times higher risk for infection than non-dog owners, increasing to 3.3 times for confirmed or probable infection, thus providing evidence that dogs are involved in transmission to humans.

This work was supported in part by the Wellcome Trust (grant number 094325/Z/10/Z) and the Swiss National Science Foundation (grant no. 31003A-173131).

\section{About the Author}

Dr. Bebezov is a surgeon and is head of the Department of Hospital Surgery in the Medical Faculty at the Kyrgyz-Russian Slavic University in the Kyrgyz Republic. His main interest is in the surgical treatment of echinococcosis with an emphasis on $\mathrm{AE}$. 


\section{References}

1. Kern P, Menezes da Silva A, Akhan O, Müllhaupt B, Vizcaychipi KA, Budke C, et al. The echinococcoses: diagnosis, clinical management and burden of disease. Adv Parasitol. 2017;96:259-369. http://dx.doi.org/10.1016/ bs.apar.2016.09.006

2. Torgerson PR, Schweiger A, Deplazes P, Pohar M, Reichen J, Ammann RW, et al. Alveolar echinococcosis: from a deadly disease to a well-controlled infection. Relative survival and economic analysis in Switzerland over the last 35 years. J Hepatol. 2008;49:72-7. http://dx.doi.org/10.1016/j.jhep.2008.03.023

3. Craig PS; Echinococcosis Working Group in China. Epidemiology of human alveolar echinococcosis in China. Parasitol Int. 2006;55(Suppl):S221-5. http://dx.doi.org/10.1016/ j.parint.2005.11.034

4. Deplazes P, Rinaldi L, Alvarez Rojas CA, Torgerson PR, Harandi MF, Romig T, et al. Global distribution of alveolar and cystic echinococcosis. Adv Parasitol. 2017;95:315-493. http://dx.doi.org/10.1016/bs.apar.2016.11.001

5. Raimkylov KM, Kuttubaev OT, Toigombaeva VS. Epidemiological analysis of the distribution of cystic and alveolar echinococcosis in Osh Oblast in the Kyrgyz Republic, 2000-2013. J Helminthol. 2015;89:651-4. http://dx.doi.org/10.1017/S0022149X15000565

6. Schweiger A, Grimm F, Tanner I, Müllhaupt B, Bertogg K, Müller N, et al. Serological diagnosis of echinococcosis: the diagnostic potential of native antigens. Infection. 2012;40:139-52. http://dx.doi.org/10.1007/s15010-011-0205-6

7. Sako Y, Nakao M, Nakaya K, Yamasaki H, Gottstein B, Lightowers MW, et al. Alveolar echinococcosis: characterization of diagnostic antigen Em18 and serological evaluation of recombinant Em18. J Clin Microbiol. 2002;40:2760-5. http://dx.doi.org/10.1128/JCM.40.8.2760-2765.2002

8. Stieger C, Hegglin D, Schwarzenbach G, Mathis A, Deplazes P. Spatial and temporal aspects of urban transmission of Echinococcus multilocularis. Parasitology. 2002;124:631-40. http://dx.doi.org/10.1017/S0031182002001749

9. Craig PS, Giraudoux P, Shi D, Bartholomot B, Barnish G, Delattre $\mathrm{P}$, et al. An epidemiological and ecological study of human alveolar echinococcosis transmission in south Gansu, China. Acta Trop. 2000;77:167-77. http://dx.doi.org/10.1016/ S0001-706X(00)00134-0

10. Bartholomot G, Vuitton DA, Harraga S, Shi DZ, Giraudoux P, Barnish G, et al. Combined ultrasound and serologic screening for hepatic alveolar echinococcosis in central China. Am J Trop Med Hyg. 2002;66:23-9. http://dx.doi.org/10.4269/ajtmh.2002.66.23

11. Hartnack S, Budke CM, Craig PS, Jiamin Q, Boufana B, Campos-Ponce $\mathrm{M}$, et al. Latent-class methods to evaluate diagnostics tests for Echinococcus infections in dogs. PLoS Neg1 Trop Dis. 2013;7:e2068. http://dx.doi.org/10.1371/ journal.pntd.0002068

12. Afonso E, Knapp J, Tête N, Umhang G, Rieffel D, van Kesteren F, et al. Echinococcus multilocularis in Kyrgyzstan: similarity in the Asian EmsB genotypic profiles from village populations of Eastern mole voles (Ellobius tancrei) and dogs in the Alay valley. J Helminthol. 2015;89:664-70. http://dx.doi.org/10.1017/ S0022149X15000474

13. Ziadinov I, Mathis A, Trachsel D, Rysmukhambetova A, Abdyjaparov TA, Kuttubaev OT, et al. Canine echinococcosis in Kyrgyzstan: using prevalence data adjusted for measurement error to develop transmission dynamics models. Int J Parasitol. 2008;38:1179-90. http://dx.doi.org/10.1016/j.ijpara.2008.01.009

Address for correspondence: Paul R. Torgerson, Vetsuisse Faculty, Section of Veterinary Epidemiology, Winterthurestrasse 270, Zurich CH-8057, Switzerland; email: paul.torgerson@access.uzh.ch

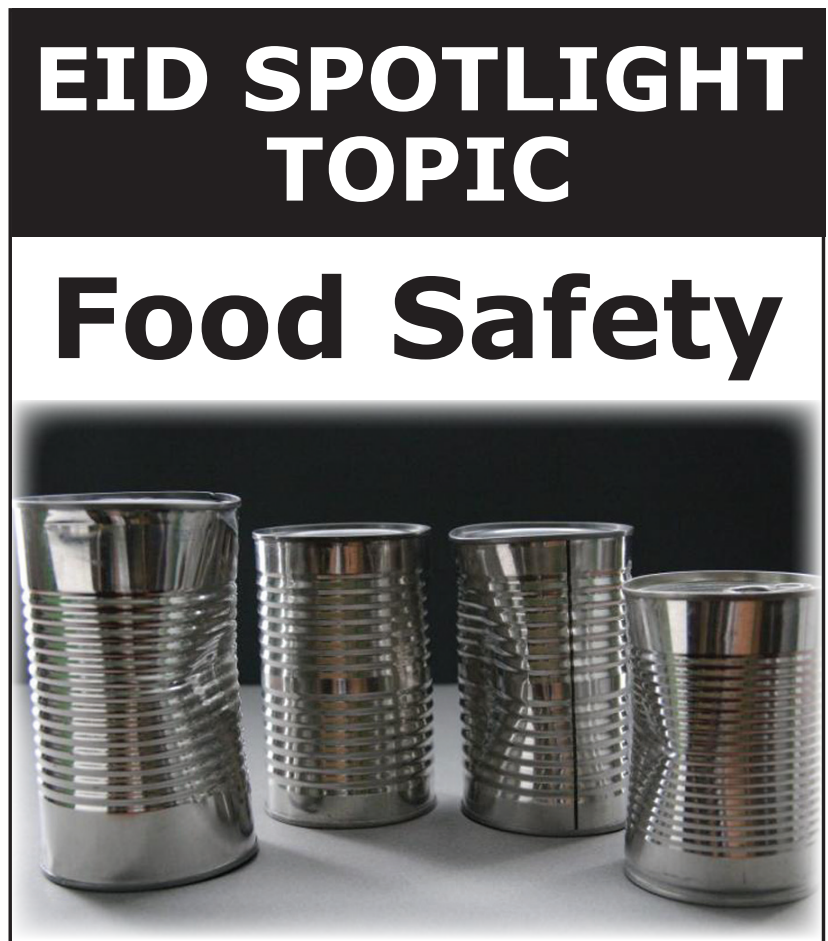

Foodborne illness (sometimes called "foodborne disease," "foodborne infection," or "food poisoning") is a common, costly-yet preventable-public health problem. Each year, 1 in 6 Americans gets sick by consuming contaminated foods or beverages. Many different disease-causing microbes, or pathogens, can contaminate foods, so there are many different foodborne infections. In addition, poisonous chemicals, or other harmful substances can cause foodborne diseases if they are present in food.

\section{http://wwwnc.cdc.gov/eid/ page/food-safety-spotlight}

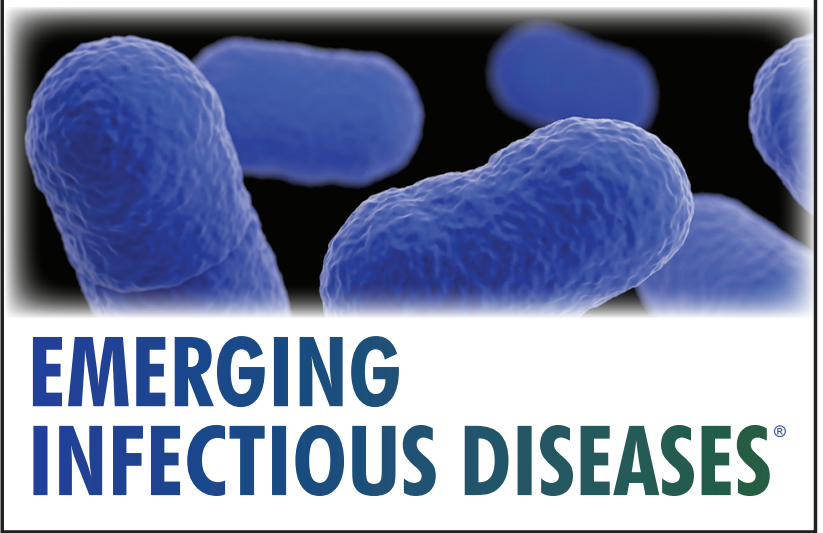

